Proceedings of the 45th International School and Conference on the Physics of Semiconductors "Jaszowiec" 2016, Szczyrk

\title{
Dye Aggregation Influence on Dye Sensitized Solar Cell Performance in Nanocoral ZnO-Based Thin Film Cells Sensitized with N-719 and Rose Bengal Dyes
}

\author{
M.A. Borysiewicz ${ }^{a *}$, S. Chusnutdinow ${ }^{b}$, M. WzoreK $^{a}$ And T. WojCIEChowski ${ }^{b}$ \\ ${ }^{a}$ Institute of Electron Technology, al. Lotników 32/46, 02-668 Warsaw, Poland \\ ${ }^{b}$ Institute of Physics, Polish Academy of Sciences, Aleja Lotnikow 32/46, PL-02668 Warsaw, Poland \\ Dye sensitized solar cells were fabricated using $\mathrm{ZnO}$ nanostructured photoelectrodes sensitized with N-719 \\ or Rose Bengal dyes. We assessed the device performance as a function of the sensitization time and found a \\ dependence on time for the N-719 and no significant changes for the Rose Bengal. Furthermore, we observe that \\ the structure of the N-719 molecule beneficial for sensitization of $\mathrm{TiO}_{2}$ may lead to the degradation of the $\mathrm{ZnO}$ \\ crystals and a growth of an amorphous shell limiting dye performance in the cells.
}

DOI: 10.12693/APhysPolA.130.1187

PACS/topics: 84.60.Jt, 81.15.Cd, 68.35.bg, 68.55.ag

\section{Introduction}

Dye sensitized solar cells (DSSCs) are a class of photovoltaic devices [1] which has been receiving significant attention due to the possibility of tailoring the absorption properties of the electrodes by sensitizing them using a large family of dyes [2]. The standard electrodes for DSSC consist of mesoporous titanium dioxide $\left(\mathrm{TiO}_{2}\right)$ nanostructures which are transparent to the visible light but yield an increased surface area for high dye coverage and efficient photon absorption. Due to the electron mobility in bulk zinc oxide $(\mathrm{ZnO})$ being $\approx 200 \mathrm{~cm}^{2} \mathrm{~V}^{-1} \mathrm{~s}^{-1}$ [3], which is two orders of magnitude higher than in $\mathrm{TiO}_{2}$ [4], $\mathrm{ZnO}$ has been regarded as promising for replacing $\mathrm{TiO}_{2}$ as the electrode material. Since the electrode morphology is relevant in the electron transport from the dye to the terminal [5] $\mathrm{ZnO}$ has an additional benefit of being synthesized in a wide array of nanoscale morphologies [6].

In this communication we report on the application of nanostructured $\mathrm{ZnO}$ electrodes in DSSCs which were synthesized by a unique approach of magnetron sputter deposition of nanoporous $\mathrm{Zn}$ with postdeposition annealing [7]. Being a large-scale vacuum technique magnetron sputtering enables high throughput stable processing, relevant for potential fabrication. Furthermore, a direct comparison of two most commonly used dyes, the ruthenium complex N-719 and Rose Bengal (RB), in one structure is performed and the properties of their interface with $\mathrm{ZnO}$ studied.

\section{Experimental}

The DSSC is a device consisting of a dye-sensitized photoanode, catalytic counter electrode, redox electrolyte and a seal/spacer. Both electrodes were prepared on fluorine-doped indium tin oxide (FTO) covered

\footnotetext{
*corresponding author; e-mail: mbory@ite.waw.pl
}

glass. The photoanode was fabricated through deposition of a nanocoral $\mathrm{Zn}$ film by magnetron sputtering with subsequent annealing in an oxygen flow at $400^{\circ} \mathrm{C}$ for $5 \mathrm{~min}$. To increase its conductivity, it was doped with hydrogen by annealing in an $\mathrm{Ar} / \mathrm{H}_{2}$ flow at $350^{\circ} \mathrm{C}$ for $3 \mathrm{~s}$. The photoelectrodes were sensitized by soaking in $0.25 \mathrm{mM}$ ethanol suspensions of the N-719 and RB dyes. The soaking times were in the range of 0.5 to $20 \mathrm{~h}$. The counter electrode was a $5 \mathrm{~nm}$ thin $\mathrm{Pt}$ film on the FTO-covered glass. Holes were drilled for electrolyte filling in the counter electrode and the cell was assembled by hot pressing the two electrodes together using a $25 \mu \mathrm{m}$ thick adhesive gasket. Finally, the structure was filled with a iodide/tri-iodide electrolyte and sealed.

We measured the cell performance using a solar simulator under 1 sun 1.5 AM conditions. Areal short circuit current density $\left(J_{\mathrm{SC}}\right)$ and open circuit voltages $\left(V_{\mathrm{OC}}\right)$ were determined, along with the filling factor $\mathrm{FF}$ and cell efficiency $\eta$. A model was fitted to the data to determine the series $\left(R_{\mathrm{s}}\right)$ and shunt $\left(R_{\mathrm{sh}}\right)$ resistivities. The model consisted of the photocurrent source, diode and shunt resistor in parallel, connected in series to the series resistor. The morphology of the sensitized photoanodes was imaged using scanning electron microscopy (SEM) and transmission electron microscopy (TEM). High resolution TEM (HR-TEM) along with energy dispersive spectroscopy (EDX) were applied to study in detail the surface of dye-loaded $\mathrm{ZnO}$.

\section{Results and discussion}

Comparing the performance of the cells sensitized with two dyes, it is evident that both the highest $J_{\mathrm{SC}}$ and $V_{\mathrm{OC}}$ are obtained with the N-719 dye (see Fig. 1). This may be due to better surface coverage of the semiconductor nanostructures. It is known that the carboxylic acid groups $(\mathrm{RCOOH})$ play a significant role in dye anchoring to the surface of $\mathrm{TiO}_{2}$ forming relatively strong intimate ester bonds [8]. Their absence in the RB molecule (see insets 

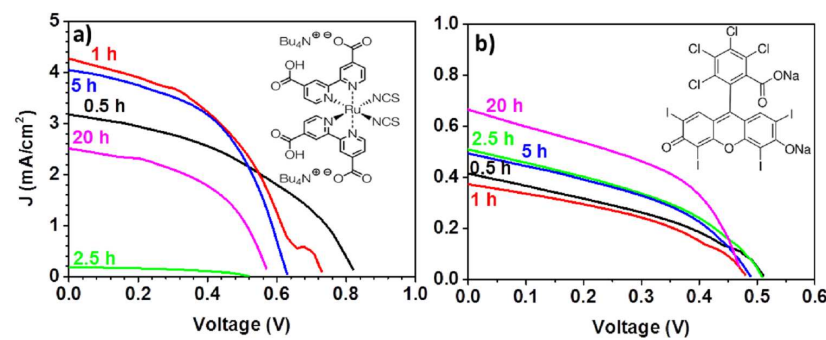

Fig. 1. Current-voltage characteristics of the illuminated cells with electrodes sensitized with (a) N-719 dye and (b) Rose Bengal dye. The insets show the molecular structure of the respective dyes.

in Fig. 1) may be the reason for decreased adsorption in our electrodes. If that would be the case, it would seem that this bond formation is much more relevant in $\mathrm{ZnO}$ than in $\mathrm{TiO}_{2}$ where $\mathrm{RB}$ has been successfully used for sensitization.

By changing the sensitization time $\left(t_{\mathrm{s}}\right)$ we can obtain different $J_{\mathrm{SC}}$ and $\eta$. In the N-719 case their dependence on time would show a maximum for $1 \mathrm{~h}$ and a decreasing trend for larger $t_{\mathrm{s}}$ (see Table I). For $t_{\mathrm{s}}=2.5 \mathrm{~h}$ very small currents can be seen and this effect was seen also when we repeated the experiment. From modelling we see that a significant increase in $R_{\mathrm{sh}}$ was observed for this sample. However, the reason for such behavior cannot be explained at the moment. For $\mathrm{RB}$ the $J_{\mathrm{SC}}$ and $\eta$ shows negligible dependence on $t_{\mathrm{s}}$. The case with $V_{\mathrm{OC}}$ is similar. Its value drops with the increase of $t_{\mathrm{s}}$ but this drop is more evident for $\mathrm{N}-719(0.25 \mathrm{~V})$ than for RB $(0.05 \mathrm{~V})$. Taking all data into account, including the modelling results, it can be said that the RB efficiency is not significantly dependent on $t_{\mathrm{s}}$ in technologically viable times.

TABLE I

Electrical parameters of the cells sensitized with the N-719 and RB dyes for increasing sensitization times $\left(t_{\mathrm{s}}\right)$.

\begin{tabular}{c|c|c|c|c|c|c}
\hline \hline $\begin{array}{c}t_{\mathrm{s}} \\
{[\mathrm{h}]}\end{array}$ & $\begin{array}{c}J_{\mathrm{SC}} \\
{\left[\mathrm{mA} / \mathrm{cm}^{2}\right]}\end{array}$ & $\begin{array}{c}V_{\mathrm{OC}} \\
{[\mathrm{V}]}\end{array}$ & $\begin{array}{c}\eta \\
{[\%]}\end{array}$ & $\begin{array}{c}\mathrm{FF} \\
{[\%]}\end{array}$ & $\begin{array}{c}R_{\mathrm{s}} \\
{[\Omega]}\end{array}$ & $\begin{array}{c}R_{\mathrm{sh}} \\
{[\mathrm{k} \Omega]}\end{array}$ \\
\hline 0.5 & 3.19 & 0.84 & 1.07 & 40 & 48 & 0.7 \\
1 & 4.74 & 0.74 & 1.37 & 39 & 11 & 0.8 \\
2.5 & 0.18 & 0.55 & 0.04 & 42 & 28 & 7.7 \\
5 & 4.18 & 0.64 & 1.34 & 50 & 17 & 0.6 \\
20 & 2.51 & 0.59 & 0.73 & 49 & 5 & 1.0 \\
\hline \multicolumn{7}{c}{ Rose Bengal } \\
\hline 0.5 & 0.83 & 0.52 & 0.17 & 40 & 77 & 1.2 \\
1 & 0.75 & 0.50 & 0.15 & 39 & 68 & 1.8 \\
2.5 & 0.79 & 0.52 & 0.17 & 41 & 23 & 1.5 \\
5 & 0.75 & 0.50 & 0.15 & 41 & 29 & 1.4 \\
20 & 0.84 & 0.48 & 0.19 & 48 & 17 & 1.3
\end{tabular}

From SEM cross-section images of the electrodes we can see that the two dyes show different behavior on the $\mathrm{ZnO}$ nanostructures. In the case of $\mathrm{RB}$, we observe no significant changes in the morphology of individual grains with increasing $t_{\mathrm{s}}$ (see Fig. 2). It is therefore confirming the above hypothesis relating the absence of carboxyl acid groups to low semiconductor adsorption. At the same time, we can see a layer of material aggregating nonuniformly on top of the $\mathrm{ZnO}$ electrode for large $t_{\mathrm{s}}$. This however is not conformal to $\mathrm{ZnO}$ and is related to self-aggregation of dye molecules. This aggregation does not block the pores and thus does not change cell performance. On the other hand, for the N-719 dye a conformal shell on the nanostructured $\mathrm{ZnO}$ is visible, most notable in the top part of the electrode.

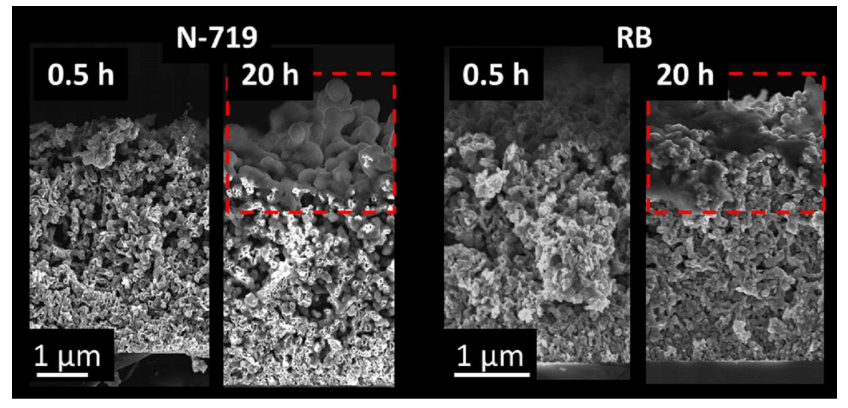

Fig. 2. SEM plan-view images of the $\mathrm{ZnO}$ electrode sensitized by N-719 and RB dyes for $0.5 \mathrm{~h}$ and $20 \mathrm{~h}$. Red lines mark areas of visible conformal coverage (N-719) and dye self-aggregation (RB)

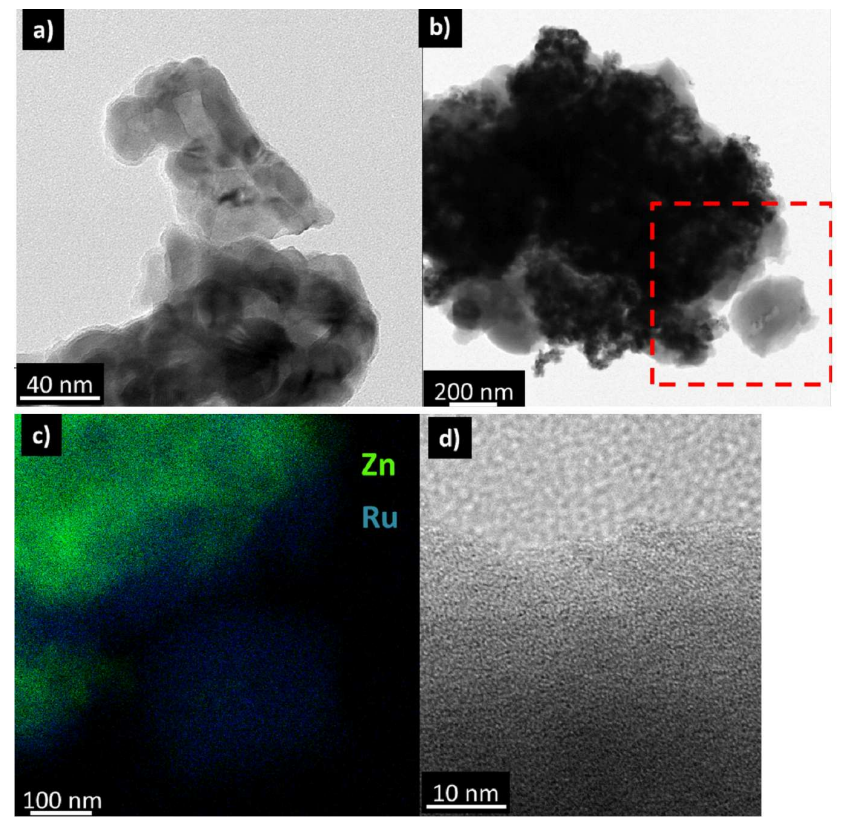

Fig. 3. TEM images of $\mathrm{ZnO}$ electrode sensitized for (a) $0.5 \mathrm{~h}$ and (b) $20 \mathrm{~h}$. (c) EDX element map of $\mathrm{Zn}$ and $\mathrm{Ru}$ atoms of the area in (b) marked in red. (d) HR TEM image of the amorphous shell.

We applied TEM investigations to understand the nature of the surface shell in the N-719 samples (see Fig. 3). 
The shell grows thicker with sensitization time and by means of EDX mapping we were able to see that there is a small amount of $\mathrm{Zn}$ in the Ru-dominant structures. Their microstructure is however atomically amorphous and they can be a product of a reaction between $\mathrm{ZnO}$ and the N-719 dye. Most probably the carboxylic acid groups led to dissolution of $\mathrm{ZnO}$ and its incorporation into the newly formed compound. Therefore, the same groups that are responsible for the high dye anchoring in $\mathrm{TiO}_{2}$ may degrade the chemically sensitive $\mathrm{ZnO}$.

\section{Conclusions}

We fabricated DSSCs with nanocoral ZnO photoanodes fabricated by means of magnetron sputter deposition with postdeposition annealing. We sensitized them with N-719 or Rose Bengal dyes. We assessed the influence of sensitization times of the cell performance finding the highest $\eta$ for $1 \mathrm{~h}(1.37 \%)$ for N-719 and no significant dependence of $\eta$ on time for Rose Bengal $(0.17 \%)$. We relate it to the difference in the chemical structure of the dye molecues. Furthermore, we observe the growth of an amorphous $\mathrm{Ru}$ and $\mathrm{Zn}$ containing shell on the $\mathrm{ZnO}$ nanocrystals in time that we think is related to high $\mathrm{ZnO}$ reactivity. Such a shell may limit the cell performance by increasing the dye recharging time from the electrolyte.

\section{Acknowledgments}

This research was supported by the Ministry of Science and Higher Education in the frames of the Iuventus Plus programme through the project "Studies on the Influence of Dye and Quantum Dot Aggregation on the Efficiency of Nanocoral ZnO-based Dye Sensitized Solar Cells", contract: 0038/IP2/2015/73.

\section{References}

[1] B. O'Reagan, M. Graetzel, Nature 353, 737 (1991).

[2] M. Ye, X. Wen, M. Wang, J. Iocozzia, N. Zhang, C. Lin, Z. Lin, Mater. Today 18, 155 (2015).

[3] D.C. Look, D.C. Reynolds, J.R. Sizelove, R.L. Jones, C.W. Litton, G. Cantwell, W.C. Harsch, Solid State Commun. 105, 399 (1998).

[4] L. Forro, O. Chauvet, D. Emin, L. Zuppiroli, H. Berger, F. Levy, J. Appl. Phys. 75, 633 (1994).

[5] P. Docampo, S. Guldin, U. Steiner, H.J. Snaith, J. Phys. Chem. Lett. 4, 698 (2013).

[6] Z.L. Wang, Mater. Today 7, 26 (2004).

[7] M.A. Borysiewicz, E. Dynowska, V. Kolkovsky, J. Dyczewski, M. Wielgus, E. Kamińska, A. Piotrowska, Phys. Status Solidi A 209, 2463 (2012).

[8] Organometallics and Related Molecules for Energy Conversion, Ed. W.Y. Wong, Springer, 2008, p. 99. 